\title{
Where Women Scientists Are the Majority
}

\author{
Women physicists from Lebanon, Palestine, Pakistan, and Egypt share \\ their thoughts about being scientists in places where women make up a \\ much larger share of STEM graduates than in Europe and in the US.
}

\section{By Matteo Rini}

$\Gamma$ rom Egypt to Pakistan, countries in the Middle East and Western Asia can appear very different from each other. But their university classrooms share a rare feature: women make up the majority of students of science, technology, engineering, and math (STEM). The picture isn't fully rosy, however. While this pipeline of women talent is strong in early educational settings, it drops off in the workplace. But a growing number of women in these places are founding start-up companies, landing faculty positions, or leading ambitious research ventures, such as the United Arab Emirates (UAE) Mars mission that put a satellite in Mars' orbit last February.

When Sana Odeh-a New York University (NYU) professor and a native of Palestine-moved to the UAE to establish the computer science department of NYU Abu Dhabi, she was elated to see this trend and decided to work to further promote STEM careers for women. She founded Arab Women in Computing

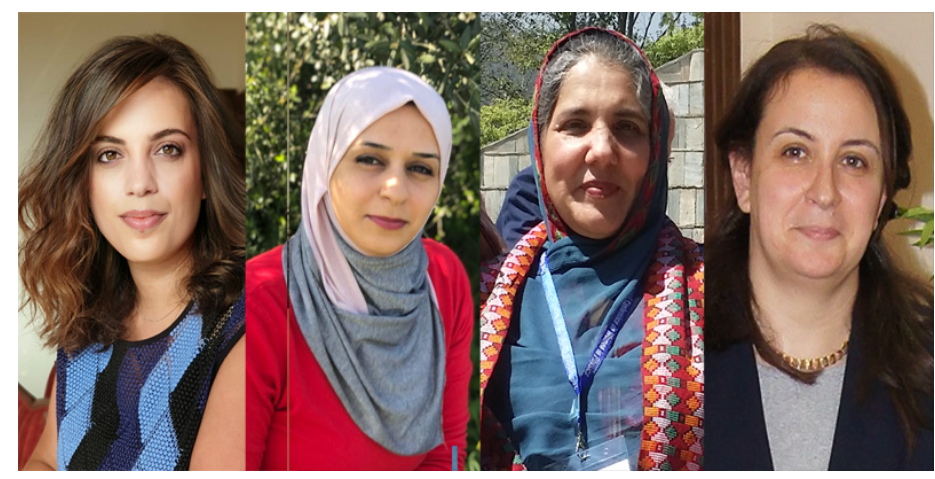

From left to right: Marie Abboud, Hadil Abualrob, Anisa Qamar, and Hoda Abou Shady. and organized hackathons, conferences, and prizes aimed at supporting women in academia, industry, and start-ups. Today she also runs a research project aimed at pinpointing the roots of the participation of women in STEM in these countries.

So why do many more women study science-related subjects in these Muslim-majority countries than in the US and Europe? Many cultural, economic, and societal factors play a role. But, Odeh says, the surveys and interviews that she conducted point at a simple explanation: "These women are passionate about science and pick fields that they think will benefit society." What's more, she says, they don't receive cues from society that science and engineering are "fields for men" which is the case in most Western countries (see Viewpoint: Why More Women Study Physics in Muslim Countries).

To learn more about life as a woman physicist in the Middle East and Western Asia, Physics interviewed science professors from Lebanon, Palestine, Pakistan, and Egypt. The interviewed physicists are Marie Abboud, who works in optical physics at Saint-Joseph University in Beirut, Lebanon; Hadil Abualrob, an accelerator physicist at the An-Najah National University in Nablus, Palestine; Anisa Qamar, who works on plasma physics at the University of Peshawar in Pakistan; and Hoda Abou Shady a nuclear physicist and the vice-dean for graduate studies at Cairo University in Egypt.

All interviews are edited for brevity and clarity.

\section{What made you want to study physics?}

"As a child I was fascinated by rainbows. Later I learned that physics-and specifically optics-could help me understand 


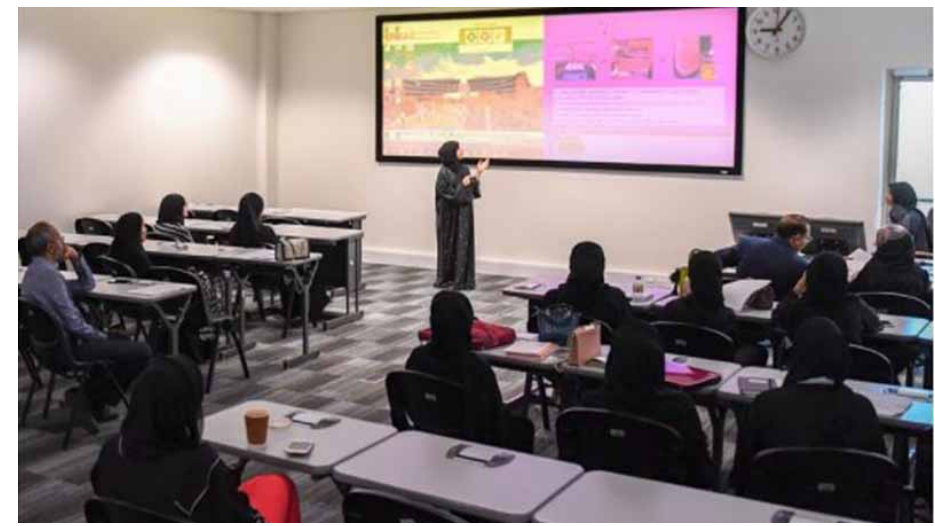

A graduate chemistry class at the United Arab Emirates University in Al Ain is attended mostly by women students.

Credit: UAEUNEWS

these beautiful arcs of colors. I realized that with optics I could both satisfy my curiosity and make useful experiments," Marie Abboud says. Today, she applies imaging techniques to study processes relevant to wine making, fruit ripening, fermentation, dental-materials engineering, and other applications.

Hadil Abualrob was lured by the most fundamental of questions: Where does the Universe come from? "Finding the answer requires probing the smallest components of matter," she says, which led her to work on particle accelerators. She is now working to create the first group working on accelerator physics in Palestine.

"From my childhood, I was inspired by the Sun, the Moon, stars, and galaxies," says Anisa Qamar, who studies plasma-the state of most of the visible matter in the cosmos.

Hoda Abou Shady picked nuclear physics motivated by the desire to develop sustainable energy sources for Egypt. "Making people's lives better is what matters to me," she says. Heeding that spirit, she recently became a member of Egypt's Presidential Advisory Board for Education and Scientific Research.

\section{How many women are there at the different levels of your institution?}

At An-Najah National University in the West Bank, women make up a remarkable $90 \%$ of physics students, a typical number throughout Palestine, says Abualrob. She notes that this high participation hasn't yet translated into faculty appointments, but she is confident a change is coming. "I was the first woman in my department to do a Ph.D. abroad, and now I am back as a professor. I hope [my achievement] will inspire more young women to choose this path."

In Pakistan, women make up around half of the undergraduate population, but women holding faculty positions are still quite rare, Qamar says. The picture is the same at Abboud's Saint Joseph University, Lebanon. "There is a clear 'glass ceiling effect,"' she says. "It's difficult for women to reach the top ranks." Less than $20 \%$ of the university's tenured physics professors are women, although she notes that this percentage is a big improvement over her undergrad times, when there were no women faculty in her department.

Egypt is perhaps unique in this context. "Most scientific departments are gender balanced all the way from undergraduate to faculty, with slight differences depending on the field," Abou Shady says. She notes that a gender gap is only noticeable at the very top: rectors, deans, and institute directors are predominantly men.

\section{What could be improved to better support women scientists in your country?}

"Eliminating the glass ceiling and making academic and family life compatible should be priorities," Abboud says. Drawing from her experience in Europe, where she did her Ph.D., she says that gender parity should be a required consideration when putting together a research consortium or establishing a hiring committee. "That's not always happening in Lebanon," she says.

Financial support for women to travel to international conferences or to carry out research stays abroad are badly needed in Pakistan, Qamar says. Throughout her career, she has faced some men professors saying that they won't offer a Ph.D. to a woman or that women aren't "apt at the practice of physics." To fight those barriers, she organized Pakistan's first international conference on women in physics. "Seeing other women playing key roles in [physics] in their region and globally will boost the confidence of Pakistani women," she says. Abou Shady also stresses the importance of role models at the highest levels: "I want to see a woman Minister of Education and a woman Foreign Minister in Egypt," she says. 
Encouraging the international mobility of women graduates is another key factor, Abualrob says. "In our society, it used to be unacceptable for a girl to go abroad to study or work," but families are warming up to the idea after seeing successful examples like hers.

\section{What advice would you give a young woman considering a career in science?}

"People will throw roadblocks at you, so fight back. If you don't fight, you'll lose all the battles," Abou Shady says. "Dream big and pursue these dreams, but also learn to redefine your priorities at different stages of your life: You don't need to sacrifice family life to be an excellent scientist," Abboud says. "Accept failure but stay positive, and focus on success," Qamar says. Work and study abroad, Abualrob says. "It is very safe, and you won't lose your cultural identity."

\section{Any advice to countries struggling with the participation of women in STEM?}

"Science is neither masculine nor feminine," Abboud says. Societies across the globe need to work together to break gender stereotypes, starting from childhood. Once these stereotypes are gone, "we will stop depriving the world of half of its potential talent," she says.

Matteo Rini is the Editor of Physics. 